\title{
Doing exercise or sport together with one's child is positively associated with mothers' momentary affect in daily life, but not with higher levels of overall physical activity
}

Martina Kanning ${ }^{1 *}$ (D), Bridgette Do², Tyler B. Mason², Britni R. Belcher ${ }^{2}$, Chih-Hsiang Yang ${ }^{2}$ and Genevieve F. Dunton ${ }^{3}$

\begin{abstract}
Background: Physical inactivity is a widespread problem with a great need for innovative intervention concepts to overcome it. Epidemiological studies have identified working women in high-income Western countries to be at greater risk for physical inactivity. The current study included working mothers and examined within-subject associations between doing exercise/sport together with one's child and five different affective states, and with light physical activity (LPA) and moderate-to-vigorous physical activity (MVPA).

Method: During 1 week, mothers $(N=192)$ completed up to eight ecological momentary assessment (EMA) surveys a day to assess momentary affect and certain situational circumstances (e.g., doing exercise/sport, being together with child). Physical activity was assessed objectively with waist-worn accelerometers.

Results: Multilevel analysis showed that doing exercise/sport together with one's child was associated with higher positive affect and lower negative affect compared to being active alone. However, greater frequency of doing exercise/sport together with children was negatively associated with MVPA.
\end{abstract}

Conclusion: Due to the positive effect on momentary affect, combining spending time together with one's child and simultaneously doing exercise/sport might be a good strategy of pairing two relevant personal goals. However, this strategy was not associated with sufficient MVPA.

Keywords: Ambulatory assessment, Ecological momentary assessment, Mood, Goal facilitation, Working mothers

\section{Background}

Physical activity has well-established positive effects on physiological health, including decreasing risk for cardiovascular disease, hypertension, diabetes, and some cancers [1-3], as well as on mental health, including reducing depression and enhancing subjective wellbeing [4-6]. Given these beneficial health effects, the relative

\footnotetext{
* Correspondence: martina.kanning@uni-konstanz.de

1 Department of Sport Science, Chair of Social and Health Sciences, University of Konstanz, Universitätsstraße 10, 78464 Constance, Germany

Full list of author information is available at the end of the article
}

reduction of insufficient physical activity is one of the nine global targets to improve the prevention and treatment of non-communicable diseases [7]. The World Health Organization (WHO) recommends at least 150 min of aerobic physical activity with moderate intensity or $75 \mathrm{~min}$ of vigorous activities per week, or equivalent combinations [8]. Nevertheless, a recently published review of 358 population-based surveys from 168 countries stated that only $27.5 \%$ (95\% CI $25.0-32.2)$ of the overall population met the WHO recommendations for aerobic physical activity [9]. Besides wide variations in inactivity

(c) The Author(s). 2020 Open Access This article is licensed under a Creative Commons Attribution 4.0 International License, which permits use, sharing, adaptation, distribution and reproduction in any medium or format, as long as you give appropriate credit to the original author(s) and the source, provide a link to the Creative Commons licence, and indicate if changes were made. The images or other third party material in this article are included in the article's Creative Commons licence, unless indicated otherwise in a credit line to the material. If material is not included in the article's Creative Commons licence and your intended use is not permitted by statutory regulation or exceeds the permitted use, you will need to obtain permission directly from the copyright holder. To view a copy of this licence, visit http://creativecommons.org/licenses/by/4.0/ The Creative Commons Public Domain Dedication waiver (http://creativecommons.org/publicdomain/zero/1.0/) applies to the data made available in this article, unless otherwise stated in a credit line to the data. 
prevalence between different regions and income groups, the pooled analysis identified that women were less physically active than men, with the greatest sex differences in high-income Western countries. In such countries, the majority of women work outside the home [10] and working mothers have been identified as a group at high risk for physical inactivity [11].

Mothers, especially of younger and of school-aged children may encounter competing demands as they attempt to balance childcare and work, which may increase barriers and challenges to participating in exercise or sport [12]. Because time is limited, these goals could conflict and mothers may have to decide between being physically active or spending time with their child, for instance. One possible solution is for mothers to engage in physical activity together with their child. According to intergoal facilitation, combining two relevant goals is associated with positive feelings given that there is both less competition between goals and goal progress [13]. Furthermore, mothers may attain sufficiently physical activity levels.

According to Diener et al. [14] goal progress is associated with positive emotions and psychological well-being: when people progress toward goals, they experience positive emotions and life satisfaction, and they experience less psychological distress. Recently, a metaanalysis of 85 studies found that successful goal pursuit was positively associated with subjective well-being with moderate-to-large effect-size [15]. However, less evidence exists on within-subject associations and on how goal progress is associated with well-being in everyday life. In two daily diary studies among married couples, effects of within-subject changes in goal progress on changes in affective states (e.g., feeling confident, happy, calm) were analyzed [16]. Daily goal progress predicted increases in positive affective states on both the same and on the following day. Also, a 20-day time-sampling study with 89 middle-aged adults assessed different strategies for managing the domains of work, family, and leisure [17]. Strategies that integrated goals from multiple domains were associated with higher overall subjective well-being (see also [17, 18]). Furthermore, a lot of evidence showed positive associations between physical activity and positive affective states in betweenperson relations (summarized in: [19]) and in withinperson relations [20]. But only view studies analyzed how situational context factors like being physically active together or alone moderate this associations [21].

Based on the existing empirical evidence, the current study analyzed the interplay between physical activity and spending time together with one's child and how it predicts affect throughout the day. Combining activity and being together with one's child might allow mothers to attain more physical activity, and as a result increase their positive mood and well-being during everyday life. Thus, the purpose of the current analysis was to investigate if spending time together with one's child or the combination of simultaneously doing exercise or sport while being together with one's child was associated with momentary positive and negative affect in everyday life. Then, regression analyses estimated how doing exercise or sport together with one's child predicted mothers' overall physical activity.

\section{Methods}

\section{Study participants}

Participants included mothers enrolled in the Mothers and Their Children's Health (MATCH) study. The MATCH study is a longitudinal observational study designed to examine the effects of maternal stress on their children's obesity risk through real-time data capture methodologies [22]. Participants were recruited through informational flyers and in-person by study staff at elementary schools and community centers in the greater Los Angeles, California area. The inclusion criteria for the MATCH study were: (1) have a child that is between 8 and 12 years old, (2) have custody of the child for at least $50 \%$ of the time, and (3) able to read and speak English or Spanish. Study exclusion criteria included: (1) report a physical health condition that may prevent physical activity, (2) currently taking medications for thyroid functions or psychological conditions such as depression, anxiety, mood disorders, and ADHD (Attention Deficit Hyperactivity Disorder), (3) currently pregnant, (4) have a child that is currently enrolled in special education programs, (5) currently using oral or inhalant corticosteroids for asthma, (6) have a child that is considered underweight by a BMI percentile $<5 \%$, and (7) work from home more than two weekday evenings per week (between the hours of 5-9 pm) or more than $8 \mathrm{~h}$ on any weekend day. Details on specific recruitment strategies and the protocol for the study are reported elsewhere [22].

A total of 202 women were enrolled in the MATCH study at baseline with their child. Ten women did not complete the ecological momentary assessment (EMA) surveys on the study smartphone, yielding 192 participants for the current analyses. Mothers' ages ranged from 24 to 57 years old $(M=41.0, S D=6.2)$, and the participating children's ages ranged from 8 to 12 years old $(M=9.6, S D=0.9)$. Participant characteristics at baseline are shown in Table 1.

\section{Procedure}

Eligible participants attended two in-person data collection sessions. During the baseline session, participants provided written informed consent. Participants also completed paper-pencil questionnaires. Mothers were 
Table 1 Participant characteristics $\left(N=202^{a}\right)$

\begin{tabular}{|c|c|}
\hline Variable & $n(\%)$ \\
\hline \multicolumn{2}{|l|}{ Working status $^{\mathrm{b}}$} \\
\hline Work full-time & $114(56.6)$ \\
\hline Work part-time & $51(25.8)$ \\
\hline Other & $33(16.7)$ \\
\hline \multicolumn{2}{|l|}{ Child sex } \\
\hline Male & $99(49.0)$ \\
\hline Female & $103(51.0)$ \\
\hline \multicolumn{2}{|l|}{ Mother race/ethnicity ${ }^{b}$} \\
\hline Hispanic/Latino & $99(49.0)$ \\
\hline Not Hispanic/Latino & $101(50.0)$ \\
\hline \multicolumn{2}{|l|}{ Child race/ethnicity ${ }^{b}$} \\
\hline Hispanic/Latino & $114(56.4)$ \\
\hline Not Hispanic/Latino & $86(42.6)$ \\
\hline \multicolumn{2}{|l|}{ Education level $^{b}$} \\
\hline Not college graduate & 79 (39.1) \\
\hline College graduate & $117(57.9)$ \\
\hline \multicolumn{2}{|l|}{ Type of household ${ }^{b}$} \\
\hline Single parent & $46(22.8)$ \\
\hline Non-single parent & $155(76.7)$ \\
\hline \multicolumn{2}{|l|}{ Annual household income } \\
\hline Less than $\$ 34,999$ & $56(27.7)$ \\
\hline$\$ 35,000-\$ 74,999$ & $49(24.3)$ \\
\hline$\$ 75,000-\$ 104,999$ & $44(21.8)$ \\
\hline Greater than $\$ 105,000$ & $53(26.2)$ \\
\hline
\end{tabular}

${ }^{\mathrm{a}}$ Data from all participants enrolled at baseline; ${ }^{\mathrm{b}}$ Datamissing on variable

loaned an Android smartphone (MotoG or Motorola X) with a data plan for the study monitoring period (Motorola Mobility, Chicago, IL). EMA data were collected through a custom software phone application for smartphones utilizing an Android operating system (Google Inc., Mountainview, CA). The study app was available in English or Spanish. Participants were trained on how to use the study application through both verbal and written instructions. EMA data were wirelessly uploaded and stored on a secure internet-accessible server.

The monitoring period lasted a total of six complete days and two partial-days. During the monitoring period, mothers were asked to carry the study smartphone with them while they were awake, aside from non-compatible activities (i.e., sleeping, showering, and swimming). Participants were instructed to connect the study phone to their home wireless Internet (Wi-Fi). If wireless connection was not available, EMA data were downloaded directly from the study phone when it was returned to the research staff.
Participants completed signal-contingent EMA surveys via the phone application through a stratified sampling scheme. Mothers were prompted up to four times per day on weekdays and up to eight times per day on weekend days. On weekdays, participants were prompted randomly once during each of the following time windows: 3:00-4:00 P.M., 5:00-6:00 P.M., 7:00-8:00 P.M., and 9: 00-9:30 P.M. On weekend days, participants were prompted randomly once during each of the following time windows: 7:00-8:00 A.M., 9:00-10:00 A.M., 11:00 A.M.-12:00 P.M., 1:00-2:00 P.M. 3:00-4:00 P.M., 5:00-6: 00 P.M., 7:00-8:00 P.M., and 9:00-9:30 P.M.

Participants reported their sleep and wake-up times to ensure that surveys were not prompted when they were asleep. Participants were notified to complete surveys through an audible prompt and/or vibration. On average, each survey took about $2 \mathrm{~min}$ to complete [23]. If no entry was made, the application sent up to two reminder signals at 3-min intervals. After the final reminder, the EMA survey became inaccessible to the participant. Participants were instructed to ignore signals during any inconvenient activities, such as driving. During the second data collection session, participants returned all study materials and were compensated. This study was conducted in accordance with the Declaration of Helsinki and all aspects of the study were approved by the Institutional Review Boards at the University of Southern California and Northeastern University (HS-12-00446).

\section{Measures}

\section{Participant characteristics}

Participants reported demographics and personal characteristics through a paper-pencil questionnaire. Demographics such as age and race/ethnicity were collected for both the mother and their participating child. In addition, participants reported their self-rated health through a single item [24], their household status (single parent household vs. not a single-parent household), and their working status. The current analyses controlled for whether the family household was not a single-parent household (0) or single-parent household (1), and whether mothers were working employed full-time (0) or employed part-time (1).

\section{Affective states}

Five affective states were based on the Positive and Negative Affect Schedule (PANAS: [25, 26]) were assessed. Each affective state was measured by the following items, respectively: "Right before the phone went off, how (1) happy, (2) calm, (3) stressed, (4) angry, and (5) sad/depressed were you feeling?" The response 
options consisted of a scale ranging from 1 (Not at all) to 4 (Extremely).

\section{Global life satisfaction}

Self-reported global life satisfaction was measured through the Satisfaction with Life Scale (SWLS: [27]) via a paper-pencil questionnaire given during the baseline session. The five-item measure includes items such as "In most ways my life is close to ideal" and "I am satisfied with my life" with a 7-point response scale ranging from 1 (Strongly disagree) to 7 (Strongly agree). A mean score was computed for the five items, with higher scores indicating higher satisfaction. The Cronbach's alpha among the study sample was .90 , indicating high internal consistency.

\section{Objective physical activity}

For the study monitoring period, continuous objective physical activity counts were collected through accelerometry. The waist-worn accelerometer (Actigraph GT3X) used 30-s epochs to collect body movement in activity counts. Intervals with $\geq 60$ continuous minutes of zero activity counts were considered as device non-wear. Only data with valid days ( $>10 \mathrm{~h}$ of device wear) was used for the analyses. Accelerometer data were timestamped in order to be matched with the EMA responses. For the within-subject analyses, the total number of physical activity counts in the 120 min leading up to an EMA prompt was used. To control for valid device wear time, only intervals with $\geq 80$ min valid device wear time within this period were included in the analyses. To estimate how doing exercise or sport together with one's child predicted mother's overall physical activity, the overall averaged minutes per day of light physical activity (LPA) and moderate to vigorous activity (MVPA) were derived used established cut-points [28] and used in the regression analyses.

Time spent with child and doing sport or exercise with child During each EMA prompt, participants indicated whether they had spent time with their child by responding to the following question: "Over the last 2 hours, have you spent time with your child (together in the same location)?" Response options were scored as 1 $(\mathrm{Yes})$ and $0(\mathrm{No})$. In addition, self-report physical activity was measured by the item "Over the last 2 hours, which of these things have you done? (check all)". Participants were given the option to select "Exercise or sports". If participants selected "Exercise or sports", the study application automatically asked the participant "Was anyone with you when you were doing exercise or sports? (check all). Response options included 1 (No (alone))", 2 (My child), 3 (Spouse/romantic partner), and 4 (Other). For the current analyses, a new variable was created to indicate whether the mother did exercise or sport alone (0) or with the child (1).

\section{Data analyses}

We conducted two sets of multilevel random coefficient regression models to investigate the within-subject effects of spending time together with one's child (together with child) (model 1a-e) and doing sport or exercise together with one's child (sport together with child) (model 2a-e) on each on five momentary affective states (happy [model 1a and 2a], calm [model $1 \mathrm{~b}$ and $2 \mathrm{~b}$ ], stressed [model 1c and 2c], angry [model 1d and 2d], and sad/depressed [model 1e and 2e]). We nested repeated prompts (level-1) within mothers (level-2) to analyze the aforementioned associations and to control for the sum of $120 \mathrm{~min}$ of physical activity counts prior to the prompt (PA) (level-1), general life-satisfaction (SWLS), and working status (WS) (both level-2). Restricted maximum likelihood estimations were used and analyses were conducted in SPSS 25. The alpha-level was set at $p<0.05$. Intra-class correlations for each dependent affect measure were estimated.

The equations for the hierarchical levels are as follows: Model 1 a-e

$$
\begin{aligned}
& \text { Level 1: } \begin{aligned}
\text { affect }_{\mathrm{ti}}= & \mathrm{b}_{0}\left(\text { constant }_{\mathrm{i}}\right)+\mathrm{b}_{1}\left(\mathrm{PA}_{\mathrm{ti}}\right) \\
& +\mathrm{b} 2(\text { together with child } \\
& \left.+\mathrm{r}_{\mathrm{ti}}\right) \\
\text { Level 2: } b_{0}= & \gamma_{00}+\gamma_{01}(\text { SWLS })+\gamma_{02}(W S) \\
& +\mu_{0 i}
\end{aligned}
\end{aligned}
$$

Model 2 a-e

$$
\begin{aligned}
& \text { Level } 1: \text { affect }_{\mathrm{t}_{\mathrm{i}}}=\mathrm{b}_{0}\left(\text { constant }_{\mathrm{ti}}\right)+\mathrm{b}_{1}\left(\mathrm{PA}_{\mathrm{ti}}\right) \\
& +\mathrm{b} 2\left(\text { sport together with } \text { child }_{\mathrm{ti}}\right)+\mathrm{r}_{\mathrm{ti}} \\
& \text { Level } 2: b_{0}=\gamma_{00}+\gamma_{01}(S W L S)+\gamma_{02}(W S) \\
& +\mu_{0}
\end{aligned}
$$

Equation 1 represents the subject's response (subscript i) for one of the five affect measures $\left(\right.$ affect $\left._{t i}\right)$ for any given EMA entry (subscript ${ }_{t}$ ). Affect $t_{t i}$ is calculated as the average intercept of one affect measure across all subjects $\left(b_{0}\right)$ and two level- 1 predictors: the sum of 120 min of physical activity counts prior diary entry $\left(b_{1}\right.$ (PA ti) ) and time spending with one's child during the last 120 min (b2 (together with child $\left.{ }_{\mathrm{ti}}\right)$ ) in Model 1 a-e and doing exercise or sport together with one's child during the last $120 \mathrm{~min}$ (b2 (sport together with child $\left.{ }_{\mathrm{t}}\right)$ ) in Model 2 a-e. Physical activity (PA) was mean-centered by groups, where the group refers to a person. In doing this, we are able to disaggregate the between- and the within-subject effects [29]. Both dichotomous variables (together with child, sport together with child) were not group-centered and used in its natural metric: together 
with child (1), doing exercise or sport together (1), and not together with child (0), and not doing exercise or sport together with child (0). Even though a predictor in its natural metric includes within- and between-person effects, this allows estimation of exact increases in affective states when the mother is together with child or doing exercise or sport together with child versus not. Random effects for each level-1 predictor were added; however, we only retained significant random effects in the final model. The random effect for the level-1 model is given by $r_{t i}$, which is assumed to have a normal distribution, "0" mean, and a variance of $\sigma^{2}$.

To control for between-subject effects, two level-2 predictors were added. Thus, this level included the fixed effects, $\gamma$ of the average intercepts and slopes across all subjects, two covariates general satisfaction with life (SWLS) and working status (WS), as well as the random effects $\left(\mu_{0 \mathrm{i}}\right)$. General satisfaction with life was grand mean-centered while working status was used in its natural metric. The random effects are assumed to be multivariate and normally distributed, with both having expected values of " 0 ".

To clarify the magnitude of significant effects, we calculated standardized effects for variables with interval scale (i.e., $P A$ and $S W L S$ ) and effect size $r$ for dichotomous variables (i.e., together with child, sport together with child, and WS). To calculate standardized effects for momentary volume of daily physical activity and general satisfaction with life (eq. 5), the standard deviation was obtained from the sample mean of total activity counts of the last 120 min before each EMA entry or the sample mean of general satisfaction with life and from the averaged within-subject mean of the corresponding affect subscale.

Standardized effect $=b_{1 i} * \mathrm{SD}(P A$ or $S W L S) / \mathrm{SD}$

(correspondent affect measure)

To reveal the differences between each of the two characteristic attributes ( 1 vs 0 ) of the three dichotomous variables, we used effective degrees of freedom to estimate effect sizes considering the nested structure of the data (Nijders and Bosker, 2011).

$$
N_{\text {effective }}=N n /\left(1+(n-1) * \rho_{\mathrm{I}}\right)
$$

$\mathrm{N} n$ indicates the number of measurement points, $n$ stands for the average number of measurement points per person, and $\rho_{\mathrm{I}}$ represents the intra-class coefficient of the corresponding affect measure (feeling happy, calm, stressed, angry, and sad/depressed). Effective degrees of freedom were analyzed with $N_{\text {effective }}$ minus the number of predictors. We calculated effect size $r$, using $t$-values and effective degrees of freedom.
To estimate the extent to which the frequency of doing exercise or sport together with one's child predicted overall LPA and MVPA (minutes/day), we averaged the dichotomous variable sport together with child per person (mother). Multiple regression analyses were used to estimate if this aggregated variable (sport together with child averaged per mother), as well as several demographics and covariates (e.g., mother or child age, child sex, mother education level, mother or child race/ ethnicity, household type, self-rated health), predicted overall LPA and MVPA (minutes/day).

\section{Results}

\section{Descriptive statistics}

Over the entire assessment period, the 192 mothers received 5818 EMA prompts, of which they completed 4445 prompts (76\%). On average, mothers completed 23 EMA surveys $(S D=7.6)$ with a range from 1 to 35 . Descriptive statistics for affect and physical activity are reported in Table 2 . The results of the intra-class coefficients were $\rho_{\mathrm{I}}=0.31, \rho_{\mathrm{I}}=0.37, \rho_{\mathrm{I}}=0.38, \rho_{\mathrm{I}}=0.5$, and $\rho_{\mathrm{I}}=0.33$ for happy, calm, stressed, angry, and sad/ depressed, respectively, indicating that $69,63,62,50$, and $67 \%$ of the respective affect measure variance was caused by within-subject variation (e.g., due to situational effects).

After removing 64 outlier situations $(\mathrm{PA}>\mathrm{Mean}+2.5$ $\mathrm{SD}$ ), participants recorded on average 27,512 counts in the 120-min window prior to the EMA prompts $(S D=$ 17,933 , median $=23,741$, range $=17-103,982$ ). Overall average minutes per day of LPA was $198.52(S D=65.95$, median $=194.56$, range $=29.06$ to 397.75 ). LPA was normally distributed. Overall average minutes per day of MVPA was $21.35(S D=15.18$; median $=17.62$, range $=$ 1.56-86.56). MVPA was log-transformed because it was not normally distributed.

In 3525 situations (79\%), mothers reported being together with their child in the same location during the last 2 hours (together with child). In 464 situations (11\%), mothers indicated that during the last 2 hours they engaged in sport or exercise. In $43 \%$ (201) of these sport or exercise situations, they did exercise or sport together with their child, and in 171 of these situations (36\%), they did exercise or sport alone. In the remaining

Table 2 Descriptive statistics of the five affect measures

\begin{tabular}{|c|c|c|c|c|c|c|}
\hline \multirow[t]{2}{*}{ Variable } & \multicolumn{2}{|c|}{ Between-subject } & \multicolumn{2}{|c|}{ Within-subject } & \multirow[t]{2}{*}{ Min } & \multirow[t]{2}{*}{ Max } \\
\hline & Mean & SD & Mean & SD & & \\
\hline Feeling happy & 2.75 & 0.48 & 2.75 & 0.80 & 1 & 4 \\
\hline Feeling calm & 2.54 & 0.48 & 2.54 & 0.89 & 1 & 4 \\
\hline Feeling stressed & 1.55 & 0.37 & 1.56 & 0.72 & 1 & 4 \\
\hline Feeling angry & 1.37 & 0.27 & 1.37 & 0.66 & 1 & 4 \\
\hline Feeling sad/depressed & 1.17 & 0.26 & 1.17 & 0.46 & 1 & 4 \\
\hline
\end{tabular}


situations (21\%), they did exercise or sport with another person (e.g., spouse or romantic partner). For the regression analyses, the situation-specific variable sport together with child was aggregated for each mother. This aggregated variable ranged from 0 (no situation in which the mother did exercise or sport with her child, $25 \%$ ) to 1 (in all situations mothers did exercise or sport with her child, $41 \%)$ and had a mean of $0.57(S D=0.42$, median $=0.62$ ).

The fixed and random effects for each of the affect measures are displayed in Table 3. Random error terms of some slopes were not significant in all models and had to be fixed because the random and the fixed variability of those slopes cannot be reliably separated. This implies that the fixed effects may vary, but they do not vary randomly as a function of general satisfaction with life and working status.

\section{Together with one's child in the same location}

In model 1a-e, we analyzed how five different affective states were predicted by being together with one's child (or not) over the past $120 \mathrm{~min}$ (see Table 3). In situations of being together with one's child, mothers felt happier (effect size $r=0.13$ ), felt calmer (effect size $r=$ 0.13 ), and felt less stressed (effect size $r=0.19$ ) compared to situations of not being together. Greater averaged counts of objectively measured PA during the prior $120 \mathrm{~min}$ predicted less calmness (standardized effect $=-0.01$ ). Furthermore, general life satisfaction was significantly associated with all affective states. According to the standardized effects, if satisfaction with life increased by 1 SD, feeling happy increased by 0.96 , feeling calm increased by 0.90 , feeling stressed decreased by 0.58 , feeling angry decreased by 0.49 , and feelings of sadness and depression decreased by 0.81 across all EMA prompts. In the model predicting feeling stressed, working status was negatively associated: mothers with a part-time job experienced more feelings of stress than mothers with a full-time job (effect size $r=0.14$ ).

\section{Doing exercise or sport together with one's child}

In model 2a-e (see Table 3), we exchanged the variable together with child with sport together with child to assess the effect of being together and simultaneously doing exercise or sport together with one's child (or not) over the past $120 \mathrm{~min}$ and five affective states. Doing exercise or sport together with one's child over the past 120 min was a significant predictor in all affect models, suggesting that when a mother did sport or exercise together with her child, she felt happier (effect size $r=$ 0.64 ), felt calmer (effect size $r=0.64$ ), felt less stress (effect size $r=0.71$ ), felt less angry (effect size $r=0.56$ ), and felt reduced sad/depressed (effect size $r=0.43$ ) compared to EMA prompts when she did exercise or sport alone. This effect was significant above and beyond the (non-significant) effects of the averaged counts of physical activity during the same time period of the prior 120 min. Similar to the models 1a-e, general satisfaction with life was positively associated with feeling happy and calm, and negatively associated with feeling angry and $\mathrm{sad} /$ depressed with no relevant changes in effect sizes. In contrast to model 1c, feeling stressed was not significantly associated with satisfaction with life $(p=.06)$. Working status did not significantly predict any affective states in these models (2a-e).

\section{Prediction of mothers overall physical activity}

Two multiple regression analyses were performed to predict overall LPA and overall MVPA. Both regression analyses were significant (LPA: $F_{(9)}=2.08, p=.037$; MVPA: $\left.F_{(9)}=2.83, p=.005\right)$ explaining $15 \%$ variance for LPA and 19\% variance for MVPA. The frequency of doing exercise or sport together with children significantly predicted MVPA $(\beta=-.24, p=.008)$. The more mothers reported doing exercise or sports alone during the assessment period, the more they engaged in MVPA. Self-rated health was significant in both models (LPA: $\beta=.21, p=.027$; MVPA: $\beta=.21, p=.039$ ), indicating that mothers who rated their general health as better also engaged in more LPA or MVPA.

\section{Discussion}

This ambulatory assessment study among 192 mothers sought to determine whether spending time together with one's child or the combination of spending time together and simultaneously doing exercise or sport together was positively associated with five momentary affective states in everyday life. In addition, the extent to which mothers do exercise or sport with their child was examined as a predictor of overall LPA and MVPA.

Results of the within-subject associations showed that mothers felt happier, calmer, and less stressed when they were with their child in daily life. This result is consistent with cross-sectional studies and theoretical assumptions about the important role of close relationships in fostering well-being and quality of life [30]. However, this study extended existing research by providing empirical evidence for within-subject relations in mother's daily life. In addition to spending time together with one's child or not, physical activity was associated with affective states: mothers who were more physically active than usual during this time period reported less calmness. There were no significant associations between doing more physical activity than usual and feelings of happiness or other negative affective states (e.g., feeling angry, sad). This pattern of findings is partly in line with other within-subject analysis of the relation between physical activity and affective states in daily life [20,31]. 
Table 3 Fixed and random effects and variance components for happy (model 1a \& 2a), calm (model 1b \& 2b), stressed (model 1c \& 2c), angry (model 1d \& 2d), and sad/depressed (model 1e \& 2e)

\begin{tabular}{|c|c|c|c|c|c|c|}
\hline Outcome & Fixed & & & Random & & \\
\hline Predictor & Coefficient SE & $\mathrm{t}$-Value $\mathrm{df}$ & $\boldsymbol{p}$-Value & Coefficient & Wald Z & 95\%-Predictive Interval ${ }^{\mathbf{a}}$ \\
\hline
\end{tabular}

\section{Feeling Happy}

Model 1a (participants: $N=183$; prompts: $n=3270$ )

$\begin{array}{llllll}\text { Intercept } & 2.578 & 0.076 & 33.873 & 2428 & <.001 \\ \text { SWLS } & 0.157 & 0.024 & 6.408 & 173 & <.001 \\ \text { Work Status } & 0.057 & 0.033 & 1.710 & 3301 & .087 \\ \text { PA (120 min) } & 8.9 \mathrm{E}-7 & 6.7 \mathrm{E}-7 & 1.331 & 3224 & .183 \\ \text { Together with child } & 0.082 & 0.031 & 2.653 & 3356 & .008\end{array}$

Model 2a (participants: $N=103$; prompts: $n=249$ )

$\begin{array}{llllll}\text { Intercept } & 2.829 & 0.195 & 14.472 & 264 & <.001 \\ \text { SWLS } & 0.115 & 0.045 & 2.427 & 113 & .013 \\ \text { Work Status } & -0.069 & 0.099 & -0.697 & 240 & .486 \\ \text { PA (120 min) } & 2.17 \mathrm{E}-6 & 1,69 \mathrm{E}-6 & 1.283 & 245 & .201 \\ \text { Sport to-gether with child } & 0.377 & 0.086 & 4.353 & 273 & <.001\end{array}$

\section{Feeling Calm}

Model 1b (paricipants: $N=182$; prompts: $n=3296$ )

$\begin{array}{llllll}\text { Intercept } & 2.34 & 0.086 & 27.051 & 2812<.001 \\ \text { SWLS } & 0.163 & 0.024 & 6.635 & 175 & <.001 \\ \text { Work Status } & 0.071 & 0.038 & 1.834 & 3307 & .067 \\ \text { PA (120 min) } & -3.0 \mathrm{E}-6 & 7.83 \mathrm{E}-7 & -3.838 & 3228 & <.001 \\ \text { Together with child } & 0.085 & 0.035 & 2.551 & 3380 & .018\end{array}$

Model 2b (participants: $N=103$; prompts: $n=249$ )

$\begin{array}{llllll}\text { Intercept } & 2.137 & 0.216 & 9.888 & 262 & <.001 \\ \text { SWLS } & 0.180 & 0.051 & 3.465 & 108 & <.001 \\ \text { Work Status } & 0.113 & 0.110 & 1.030 & 234 & .304 \\ \text { PA (120 min) } & -1.8 \mathrm{E}-7 & 1,8 \mathrm{E}-6 & -0.098 & 239 & .922 \\ \text { Sport to-gether with child } & 0.388 & 0.096 & 4.039 & 271 & <.001\end{array}$

\section{Feeling stressed}

Model 1c (participants: $\mathrm{N}=183$; prompts: $n=3268$ )

\begin{tabular}{|c|c|c|c|c|c|c|c|c|c|c|c|}
\hline Intercept & 1.810 & 0.072 & 25.127 & 2848 & $<.001$ & 0.106 & 0.014 & 7.525 & $<.001$ & 0.08 & 0.13 \\
\hline SWLS & -0.085 & 0.020 & -4.051 & 170 & $<.001$ & & & & & & \\
\hline Work Status & -0.087 & 0.032 & -2.666 & 3304 & .008 & & & & & & \\
\hline PA (120 min) & $6.8 \mathrm{E}-7$ & $6.5 \mathrm{E}-7$ & 1.046 & 3223 & .296 & & & & & & \\
\hline Together with child & -0.106 & 0.030 & -3.552 & 3382 & $<.001$ & 0.023 & 0.011 & 2.081 & .037 & 0.01 & 0.06 \\
\hline \multicolumn{12}{|c|}{ Model 2c (participants: $N=103$; prompts: $n=249$ ) } \\
\hline Intercept & 1.915 & 0.175 & 10.890 & 268 & $<.001$ & 0.107 & 0.034 & 3.101 & .002 & 0.06 & 0.20 \\
\hline SWLS & -0.07 & 0.036 & -1.885 & 99 & .062 & & & & & & \\
\hline Work Status & -0.152 & 0.090 & -1.673 & 250 & .095 & & & & & & \\
\hline PA (120 min) & $1.6 \mathrm{E}-6$ & $1.6 \mathrm{E}-6$ & -0.168 & 315 & .313 & & & & & & \\
\hline Sport to-gether with child & -0.311 & 0.077 & -4.037 & 277 & $<.001$ & & & & & & \\
\hline
\end{tabular}

\section{Feeling Angry}

Model 1d (participants: $N=183$; prompts: $n=3267$ ) 
Table 3 Fixed and random effects and variance components for happy (model 1a \& 2a), calm (model 1b \& 2b), stressed (model 1c \& 2c), angry (model 1d \& 2d), and sad/depressed (model 1e \& 2e) (Continued)

\begin{tabular}{|c|c|c|c|c|c|c|c|c|c|c|c|}
\hline \multirow{2}{*}{$\begin{array}{l}\text { Outcome } \\
\text { Predictor } \\
\end{array}$} & \multicolumn{5}{|l|}{ Fixed } & \multicolumn{6}{|l|}{ Random } \\
\hline & Coefficient & SE & t-Value & $d f$ & $\boldsymbol{p}$-Value & Coefficient & SD & Wald Z & $p$-value & 95\%-Pres & erval ${ }^{a}$ \\
\hline SWLS & -0.066 & 0.015 & -4.362 & 161 & $<.001$ & & & & & & \\
\hline Work Status & -0.032 & 0.032 & -1.015 & 3228 & .310 & & & & & & \\
\hline PA (120 min) & $1.1 \mathrm{E}-6$ & $6.3 \mathrm{E}-7$ & 1.680 & 3139 & .093 & & & & & & \\
\hline Together with child & -0.001 & 0.028 & -0.041 & 3322 & .968 & & & & & & \\
\hline \multicolumn{12}{|c|}{ Model 2d (participants: $N=103$; prompts: $n=249$ ) } \\
\hline Intercept & 1.625 & 0.206 & 7.864 & 270 & $<.001$ & 0.048 & 0.025 & 1.918 & .05 & .02 & .13 \\
\hline SWLS & -0.094 & 0.032 & -2.937 & 94 & .004 & & & & & & \\
\hline Work Status & -0.090 & 0.016 & -0.852 & .268 & 395 & & & & & & \\
\hline PA (120 min) & $-8.4 \mathrm{E}-7$ & $1.6 \mathrm{E}-6$ & -0.520 & 264 & .604 & & & & & & \\
\hline Sport to-gether with child & -0.201 & 0.075 & -2.668 & 265 & .008 & & & & & & \\
\hline \multicolumn{12}{|l|}{ Feeling sad/depressed } \\
\hline \multicolumn{12}{|c|}{ Model 1e (participants: $N=183$; prompts: $n=3270$ ) } \\
\hline Intercept & 1.224 & 0.045 & 26.678 & 2505 & $<.001$ & 0.056 & 0.007 & 8.023 & $<.001$ & .04 & .07 \\
\hline SWLS & -0.076 & 0.014 & -5.352 & 173 & $<.001$ & & & & & & \\
\hline Work Status & -0.017 & 0.020 & -0.870 & 3222 & .385 & & & & & & \\
\hline PA (120 min) & $1,5 \mathrm{E}-7$ & $3.9 \mathrm{E}-7$ & 0.402 & 3143 & .402 & & & & & & \\
\hline Together with child & -0.021 & 0.018 & -1.152 & 3274 & .249 & & & & & & \\
\hline \multicolumn{12}{|c|}{ Model 2e (participants: $N=103$; prompts: $n=249$ ) } \\
\hline Intercept & 1.299 & 0.126 & 10.275 & 265 & $<.001$ & 0.050 & 0.012 & 4.054 & $<.001$ & .03 & .08 \\
\hline SWLS & -0.127 & 0.023 & -5.408 & 123 & $<.001$ & & & & & & \\
\hline Work Status & -0.054 & 0.065 & -0.828 & 259 & .409 & & & & & & \\
\hline PA (120 min) & 3.6 E-7 & $9.9 \mathrm{E}-7$ & 0.369 & 248 & .712 & & & & & & \\
\hline Sport to-gether with child & -0.116 & 0.047 & -2.460 & 268 & .015 & & & & & & \\
\hline
\end{tabular}

${ }^{\mathrm{a}}$ Based on the assumption of normally distributed regression coefficients, the $95 \%$ predictive interval indicates the range of values between which $95 \%$ of the regression coefficients are estimated to lie (Hox, 2010). The intervals were calculated based on a model without Level 2 predictors

In a review of the effects of physical activity in daily life on subsequent affective states, most studies reported evidence of associations between more positive affect and greater physical activity, whereas there were inconsistent effects for physical activity decreasing subsequent negative affect [20]. Furthermore, most evidence suggested that physical activity increased feelings of energy rather than feelings of happiness. However, effects on calmness were inconsistent; some studies showed that people do not feel relaxed and calm while being physically active. People might feel more relaxed, but only after a time delay when the direct exhaustion of being active passes [32].

In addition to spending time together with one's child, simultaneously doing sport or exercise together was associated with more positive affect and lower negative affect. This finding expands existing results because we used this EMA study to analyze moderating effects of situational circumstances on the association between affective states and physical activity in daily life.
According to the result, doing sport or exercise together with one's child positively moderated the association between physical activity and affective states. Although this study did not analyze personal goals directly, the results may be explained by the possibility that doing sport and exercise with one's child involves the facilitation of dual goals (i.e., exercising and spending time with one's child), which may increase positive affect. Our findings are in line with former studies about the effects of goal facilitation on subjective wellbeing, although these former studies analyzed other combinations of two goals (e.g. inter-domain relationships across work and family) [33]. In an EMA study analyzing within-subject relations [17], participants reported how regular daily activities (e.g., reading, eating, talking) facilitated personal goals and their current affective state. Participants felt better and reported higher goal facilitation in situations where they did something that concerned more than one life domain. 


\section{Effects of exercise or sport with children on LPA and MVPA}

Mothers had more MVPA minutes when they were physically active alone. Thus, although doing exercise or sport together with one's child was associated with better momentary feelings, it was also negatively associated with overall MVPA. Mothers had more MVPA minutes when they were physically active alone. One possible explanation could be, that doing exercise or sport together with the child may include activities that are more intermittent or of lower intensity than the MVPA threshold. Furthermore, mother's attention may focus on watching their kid(s) and ensure their safety, instead of fully engage in sports and exercising for their own benefits, compared to when the exercise alone. Also, mothers who are not frequently engaging in exercise or sport with her child may have other strategies in her daily life to integrate MVPA (e.g., active transportation or active housework).

\section{Limitations and future directions}

Although this study was one of the first to assess withinsubject variations of affective states associated with spending time together with one's child and doing exercise or sport together with one's child, there are several limitations worth noting. First, we did not explicitly assess if spending time with one's child or being sufficiently physically active were relevant personal goals to mothers. The majority of mothers reported primarily doing exercise or sport together with their child (41\%), while $25 \%$ reported almost never doing exercise or sport with their child and the remaining third varied across the EMA period. However, this study did not explicitly assess if this $41 \%$ of mothers had the goal to do exercise or sport together with their child. While some mothers may have goals to spend time together with their child while doing exercise or sport, others may do exercise and sport to reach other personal goals. Mothers might have personal goals for activity (e.g., having fun, meeting friends, experience), but those goals may not allow them to meet the WHO-recommendation for being sufficiently physically active. Future studies should evaluate the extent to which being together with one's child and doing exercise or sport are personally relevant goals for mothers. Furthermore, there is a need for more research analyzing the effect of goal facilitation on the performance of physical activity. Doing exercise or sport, which may simultaneously lead to progress in another relevant goal, might support mothers in achieving recommended physical activity levels.

Another limitation of the study is that the waist-worn accelerometer is not an ideal measurement to capture PA from cycling [34] and because our accelerometer was not waterproof, it was not able to access swimming activities [34]. These activities may be common for mothers and children to engage in unstructured activities during leisure time together [35]. A further limitation is that participants might have understood the daily-diary question about exercise and sport in different ways. Although all participants received a definition which activities fit to this question, there could be between person differences in rating everyday life activities like walking correctly.

In addition, the current analyses did not differentiate between weekend and weekday patterns; weekends provide more opportunities for doing exercise or sport together.

\section{Conclusions}

This study showed that mothers of 8 to 12-year-old children experienced happier and calmer feelings and reduced stress in daily life when they were with their children. This positive effect on momentary affective states remained when mothers did exercise or sport with their child and was also associated with reduced feelings of anger and sadness. Therefore, doing exercise or sport together with one's child might be a good strategy of pairing two goals relevant to spending time with children and health. Furthermore, doing exercise or sport together with one's child may be a useful health promotion strategy for increasing physical activity given that positive affect can increase physical activity [36]. However, in this study, combining spending time together with one's child and doing exercise or sport was negatively associated with physical activity.

\section{Abbreviations \\ LPA: Light physical activity; MVPA: Moderate-to-vigorous physical activityEMAEcological momentary assessment}

\section{Acknowledgements}

Not Applicable.

\section{Authors' contributions}

MK formulated the research question, interpreted the data, drafted the work, and substantively the work. BD drafted the work regarding study procedures/sample and substantially revised the work. TBM substantially revised the work. BRB substantially revised the work. CY assisted in analysis, contributed to the interpretation of data, and revised the work. GFD conceptualized and designed the study and revised the work. All authors have read and approved the submitted manuscript.

\section{Funding}

NIH R01HL119255.

This work was supported by the National Heart, Lung, and Blood Institute of the National Institutes of Health (R01HL119255) and the American Cancer Society (118283-MRSGT-10-012-01CPPB). The funders had no role in the design of the study, data collection, interpretation of the day, or in writing the manuscript.

Availability of data and materials

The datasets used and/or analysed during the current study are available from the corresponding author on reasonable request. 


\section{Ethics approval and consent to participate}

All procedures followed were in accordance with the ethical standards of the responsible committee on human experimentation (institutional and national) and with the Helsinki Declaration of 1975, as revised in 2000. Written informed consent was obtained from all participants. The study was approved by the Institutional Review Boards at the University of Southern California and Northeastern University (Reference Number: HS-12-00446).

\section{Consent for publication}

Not applicable.

\section{Competing interests}

Britni R. Belcher is a member of the BMC Public Health Editorial Board. All other authors (Martina Kanning, Bridgette Do, Tyler B. Mason, Chih-Hsiang Yang, and Genevieve F. Dunton) declare that they have no conflicts of interest.

\section{Author details}

${ }^{1}$ Department of Sport Science, Chair of Social and Health Sciences, University of Konstanz, Universitätsstraße 10, 78464 Constance, Germany. ${ }^{2}$ Department of Preventive Medicine, University of Southern California, Los Angeles, CA, USA. ${ }^{3}$ Departments of Preventive Medicine and Psychology, University of Southern California, Los Angeles, CA, USA.

\section{Received: 3 February 2020 Accepted: 6 May 2020}

Published online: 19 May 2020

\section{References}

1. Powell KE, Paluch AE, Blair SN. Physical activity for health: what kind? How much? How intense? On top of what? Annu Rev Public Health. 2011;32: 349-65.

2. Lee I-M, Shiroma EJ, Lobelo F, Puska P, Blair SN, Katzmarkzyk PT. Effects of physical inactivity on major non-communicable diseases worldwide: an analysis of burden of disease and life expectancy. Lancet. 2012;380(9838): 219-29.

3. Hallal PC, Anderson LB, Bull FC, Guthold R, Haskell WL, Ekelund U. Global physical activity levels: surveillance Progress, pitfalls, and prospects. Lancet. 2012;380(9838):247-57.

4. Béland M, Lavoie KL, Briand S, White UJ, Gemme C, Bacon SL. Aerobic exercise alleviates depressive symptoms in patients with a major noncommunicable chronic disease: a systematic review and meta-analysis. $\mathrm{Br} J$ Sports Med. 2019;54:272-8 Online First: 06 February 2019.

5. Vallance JK, Winkler EA, Gardiner PA, Healy GN, Lynch BM, Owen N. Associations of objectively-assessed physical activity and sedentary time with depression: NHANES (2005-2006). Prev Med. 2011;53(4-5):284-8.

6. Wicker P, Frick B. Intensity of physical activity and subjective well-being: an empirical analysis of the WHO-recommendations. J Public Health. 2016; 39(2):e19-26.

7. WHO. Global action plan for the prevention and control of noncommunicable disease. 2013-20202013.

8. World Health Organization. Global recommendations on physical activity for health. Geneva: WHO Press, World Health Organization; 2010.

9. Guthold R, Stevens GA, Riley LM, Bull FC. Worldwide trends in insufficient physical activity from 2011 to 2016: a pooled analysis of 358 populationbased surveys with 1.9 million participants. Lancet Global Health. 2018;6: e1077-e86.

10. Bureau of Labor Statistics, U.S. Department of Labor, The Economics Daily, Labor force participation rate of mothers, 1975-2007 on the Internet at https://www.bls.gov/opub/ted/2009/jan/wk1/art04.htm (visited May 13, 2020).

11. Mailey E, McAuley E. Impact of a brief intervention on physical activity and social cognitive determinants among working mothers: a randomized trial. J Behav Med. 2014:37(2):343-55.

12. Mailey E, Huberty J, Dinkel D, McAuley E. Physical activity barriers and facilitators among working mothers and fathers. BMC Public Health. 2014; 14(657):1-9.

13. Riediger M, Freund $A M$. Interference and facilitation among personal goals: differential associations with subjective well-being and persistent goal pursuit. PSPB. 2004;30(12):1511-23.

14. Diener E, Suh EM, Lucas RE, Smith HL. Subjective well-being: three decades of progress. Psychol Bull. 1999;125(2):276-302.
15. Klug HJP, Maier GW. Linking goals Progress and subjective well-being: a meta-analysis. J Happiness Stud. 2015;16:37-65.

16. Jakubiak BK, Feeney BC. Daily goal progress is facilitated by spousal support and promotes psychological, physical, and relational well-being throughout adulthood. J Pers Soc Psychol. 2016;111(3):317-40.

17. Knecht M, Freund AM. Boundary management: a time-sampling study on managing work and private life in middle adulthood. Res Hum Dev. 2016; 13:297-311.

18. Baltes PB, Clark MA, Chakrabarti M. Work-Life Balance: the Roles of WorkFamiliy Conflict and Work-Family Facilitation. Garcea N, Harrington S, Linley PA, editors. https://www.oxfordhandbooks.com/view/10.1093/oxfordhb/ 9780195335446.001.0001/oxfordhb-9780195335446-e-162009.

19. Biddle SJH, Mutrie N, Gorely T. Psychology of physical activity: Determinants , well-being and interventions. 3rd ed. London and New York: Routledge Taylor \& Francis; 2015

20. Liao Y, Shonkoff ET, Dunton GF. The acute relationships between affect, physical feeling states, and physical activity in daily life: a review of current evidence. Front Psychol. 2015;6:1-7.

21. Dunton GF, Liao Y, Intille S, Huh J, Leventhal A. Momentary assessment of contextual influences on affective response during physical activity. Health Psychol. 2015;34(12):1145-53.

22. Dunton GF, Liao Y, Dzubur E, Leventhal AM, Huh J, Gruenewald T, et al. Investigating within-day and longitudinal effects of maternal stress on children's physical activity, dietary intake, and body composition: protocol for the MATCH study. Contemp Clin Trials. 2015;43:142-54.

23. Dzubur E, Huh J, Maher JP, Intille SS, Dunton GF. Response patterns and intra-dyadic factors related to compliance with ecological momentary assessment among mothers and children. Transl Behav Med. 2018;8(2):233-42.

24. Rohrer JE, Herman DC, Merry SP, Naessens JM, Houston MS. Validity of overall self-rated health as an outcome measure in small samples: a pilot study involving a case series. J Eval Clin Pract. 2009;15(2):366-9.

25. Watson D, Clark L. Measurement and mismeasurement of mood: recurrent and emergent issues. J Person Assess. 1997;68(2):267-96.

26. Watson DC, Tellegen A. Development and vilidation of brief measures of positive and negative affect: the PANAS scale. J Pers Soc Psychol. 1988;54: 1063-70.

27. Diener E, Emmons RA, Larsen RJ, Griffin S. The satisfaction with life scale. J Person Assess. 1985;49:71-5.

28. Troiano RP, Berrigan D, Dodd KW, Masse LC, Tilert T, Mcdowell M. Physical activity in the United States measured by accelerometers. Med Sci Sports Exerc. 2008:40:181-8.

29. Raudenbush SW, Bryk AS. Hierarchical linear models. 2nd ed. Thousands Oaks: Sage Publications; 2002.

30. Kahneman D, Diener E, Schwarzer N. Well-being: the foundations of hedonic psychology. New York: Russell Sage Foundation; 1999.

31. Kanning M, Ebner-Priemer U, Schlicht W. How to investigate within-subject associations between physical activity and affective states in everyday life: a position statement based on a literature overview. Front Psychol. 2013:4:1-16.

32. Kanning M, Ebner-Priemer UW, Brand R. Autonomous regulation mode moderates the effect of actual physical activity on affective states: an ambulant assessment approach to the role of self-determination. J Sport Exerc Psychol. 2012;34:260-9.

33. Wiese BS, Salmela-Aro K. Goal conflict and facilitation as predictors of workfamily satisfaction and engagement. J Vocat Behav. 2008;73:490-7.

34. Hansen BH, Bortnes I, Hildebrand M, Holme I, Kolle E, Anderssen SA. Validity of the Actigraph GT1M during walking and cycling. J Sports Sci. 2014;32(6):510-6.

35. Thompson JL, Jago R, Brockman R, Cartwright K, Page AS, Fox KR. Physcially active families - de-bunking the myth? A qualitative study of family participation in physical activity. Child Care Health Dev. 2009;36(2):265-74.

36. Jekauc D, Brand R. How do emotions and feelings regulate physical activity? Front Psychol. 2017;8:1145

\section{Publisher's Note}

Springer Nature remains neutral with regard to jurisdictional claims in published maps and institutional affiliations. 